\title{
ZDI839 ('Iressa'), a specific oral epidermal growth factor receptor-tyrosine kinase inhibitor, potentiates radiotherapy in a human colorectal cancer xenograft model
}

\author{
KJ Williams*,', BA Telfer', IJ Stratford' and SR Wedge ${ }^{2}$ \\ 'School of Pharmacy and Pharmaceutical Sciences, University of Manchester, Manchester MI3 9PL, UK; ${ }^{2}$ Cancer and Infection Bioscience, AstraZeneca, \\ Alderley Park, Macclesfield, Cheshire SKIO 4TG, UK
}

The effect of ZDI839 ('Iressa'), a specific inhibitor of the tyrosine kinase activity of the epidermal growth factor receptor, on the radiation response of human tumour cells (LoVo colorectal carcinoma) was evaluated in vitro and in vivo. ZDI839 (0.5 $\mu \mathrm{M}$, incubated days I -5) significantly increased the anti-proliferative effect of fractionated radiation treatment (2 Gy day ${ }^{-1}$, days $I-3)$ on LoVo cells grown in vitro $(P=0.002)$. ZDI 839 combined with either single or fractionated radiotherapy in mice bearing LoVo tumour xenografts, also produced a highly significant increase in tumour growth inhibition $(P \leqslant 0.00 \mathrm{I})$ when compared to treatment with either modality alone. The radio-potentiating effect of ZDI839 was more apparent when radiation was administered in a fractionated protocol. This phenomenon may be attributed to an anti proliferative effect of ZDI839 on tumour cell re-population between radiotherapy fractions. These data suggest radiotherapy with adjuvant ZDI839 could enhance treatment response. Clinical investigation of ZDI839 in combination with radiotherapy is therefore warranted.

British Journal of Cancer (2002) 86, II57- |161. DOI: 10.1038/sj/bjc/6600।82 www.bjcancer.com

(c) 2002 Cancer Research UK

Keywords: ZD I839; EGFR-TKI; radiotherapy; LoVo xenograft; Iressa

The epidermal growth factor receptor (EGFR) is a transmembrane glycoprotein consisting of an external ligand binding domain, a transmembrane domain and an intracellular tyrosine kinase domain. EGFR activates downstream signalling pathways involved in cell proliferation and survival, such as the Ras/Raf/MAPK and the PI3-K/Akt pathways, in response to the binding of structurally related ligands such as EGF and transforming growth factor $\alpha$ $(\mathrm{TGF} \alpha)$ (reviewed in Salomon et al, 1995). Expression or overexpression of EGFR is frequently observed in human cancers including non-small cell lung cancer and hormone-refractory prostate cancer (Salomon et al, 1995), and over expression has been associated with poor prognosis in several cancer types, including breast (Sainsbury et al, 1987), pancreas (Dong et al, 1998) and laryngeal (Maurizi et al, 1996). This observation provided the rationale for the development of inhibitors of the EGFR-mediated signalling cascade as anticancer therapeutics (Ciardiello, 2000a). ZD1839 ('Iressa') is an orally active, selective EGFR-TKI (epidermal growth factor receptor-tyrosine kinase inhibitor) that blocks signal transduction pathways implicated in the proliferation and survival of cancer cells, and other host-dependent processes promoting cancer growth. ZD1839 is currently in Phase III development for non-small cell lung cancer and in Phase II clinical trials in a number of other tumour types, and has demonstrated promising antitumour activity with good tolerability in Phase I dose-escalation studies (Baselga et al, 2000; Ferry et al, 2000). Recently, in

*Correspondence: KJ Williams; E-mail: Kaye.Williams@man.ac.uk Received I5 October 200 I; revised 4 January 2002; accepted 10 January 2002 vitro studies have revealed that ionising radiation stimulates EGFR-mediated MAPK activation (Schmidt-Ullrich et al, 1997). Enhanced signalling via this pathway affords a proliferative (Schmidt-Ullrich et al, 1997; Dent et al, 1999; Reardon et al, 1999) and survival advantage (Dent et al, 1999) in response to radiation treatment. The purpose of the present study was to evaluate whether ZD1839 overcomes this resistance pathway and hence influences the response of a human colorectal carcinoma cell line (LoVo) to radiation treatment in vitro and when grown as tumour xenografts in nude mice.

\section{MATERIALS AND METHODS}

\section{Cell line details}

The LoVo human colorectal carcinoma cell line was obtained from ECACC. All cell culture reagents were obtained from Gibco BRL. Cells were maintained in RPMI medium supplemented with $10 \%$ foetal calf serum and $2 \mathrm{~mm}$ glutamine and routinely screened for the presence of mycoplasma (Mycotect assay; Gibco BRL).

\section{In vitro studies}

The procedure used for the in vitro evaluation of ZD1839 in combination with radiation was adapted from previously published methods (Dent et al, 1999). Exponentially growing LoVo cells were sub-cultured into duplicate 24 -well plates (Falcon) at $5 \times 10^{-3}$ cells per well and left for $24 \mathrm{~h}$. Cells in both plates were exposed to ZD1839 at a range of concentrations $(0.05-0.5 \mu \mathrm{M})$ diluted from a $10 \mathrm{~mm}$ stock in DMSO using pre-warmed RPMI medium. Thirty 
minutes after drug exposure, one plate was irradiated with $2 \mathrm{~Gy}$ (X-ray, delivered at a dose rate of 0.75 Gy per min) and the second sham-irradiated. The radiation procedure was performed again 24 and $48 \mathrm{~h}$ later (total dose $6 \mathrm{~Gy}$ ). Prior to the final dose, freshly prepared ZD1839 was applied to the plates and the plates incubated for $72 \mathrm{~h}$. The replenishment of medium and ZD1839, $48 \mathrm{~h}$ through the 5 day period was performed to ensure consistent drug exposure for the duration of the assay, since our preliminary experiments with ZD1839 alone were based on a $72 \mathrm{~h}$ incubation and previous experiments with ZD1839 in vitro have used drug replenishment (Ciardiello et al, 2000b). Cell proliferation was then analysed by MTT (3-4,5 dimethylthiazol-2, 5 diphenyl tetrazolium bromide) assay (Carmichael et al, 1987). MTT ( $1 \mathrm{mg} \mathrm{ml}^{-1}$ in PBS) was added to each experimental well to a final concentration of $0.5 \mathrm{mg} \mathrm{ml}^{-1}$. Cells were incubated for $4 \mathrm{~h}$ at $37^{\circ} \mathrm{C}$, the MTT containing medium was removed and $1 \mathrm{ml}$ DMSO added per well. Plates were shaken and the optical density (OD) read at $540 \mathrm{~nm}$ using a multiwell plate reader (Titertek Twinreader).

In data analysis, pooled $\mathrm{OD}_{540 \mathrm{~nm}}$ values from replicate experiments were used to determine drug or radiation effects on proliferation. Drug-dependent growth inhibition was calculated relative to either untreated (sham-irradiated) or radiation only treated controls, in individual experiments, and the mean value from $4-5$ replicate experiments calculated.

\section{Xenograft studies}

Exponential phase LoVo cells were prepared at a $5 \times 10^{7}$ per $\mathrm{ml}$ concentration in serum-free RPMI medium. Xenografts were established by the intra-dermal injection of a $0.1 \mathrm{ml}$ volume of the prepared cell stock, $1 \mathrm{~cm}$ from the tail base on the midline of female nude mice (cba nu/nu) aged 8-10 weeks. Once a palpable tumour was apparent, tumour volume was measured daily, using calipers. Radiotherapy was administered at a dose rate of $2 \mathrm{~Gy}$ per min to unanaesthetised mice restrained in polyvinyl jigs with lead shielding and a cut away section to allow local irradiation of the tumour by the unilateral beam (Pantac X-ray set; Sheldon and Hill, 1977). Jigs were turned through $180^{\circ}$ halfway through the radiation exposure time to provide a uniform dosing. For ethical reasons, experiments were terminated when a relative tumour volume four times that at the initiation of therapy $\left(\mathrm{RTV}_{4}\right)$ was achieved. All procedures were carried out in accordance with the Scientific Procedures Act 1986 by approved protocols (Home Office Project License number $40-1770$ ) and with ethical committee approval. The ethical guidelines that were followed meet the standards required by the UKCCCR guidelines (Workman et al, 1998). Initial experiments were performed to ascertain the response of the LoVo xenograft to single-dose radiotherapy. Tumours were irradiated at 5, 10 and $15 \mathrm{~Gy}$ to obtain a dose response curve for this xenograft model. The anti-tumour effect of ZD1839 in combination with single- and fractionated-dose radiotherapy was addressed in two separate protocols. Tumour-bearing mice were randomly assigned into groups to receive either ZD1839 $\left(100 \mathrm{mg} \mathrm{kg}^{-1}\right)$ or $0.5 \%$ polysorbate vehicle, once daily by oral administration $(0.1 \mathrm{ml}$ per $10 \mathrm{~g}$ body weight) for 14 days. This was administered alone, or combined with a single X-ray dose of 5 Gy (Protocol 1) or three multiple fractions of 2 Gy (Protocol 2) delivered at $24 \mathrm{~h}$ intervals. All treatments were performed on mice bearing xenografts of $220-280 \mathrm{~mm}^{3}$ in volume. Radiotherapy was administered $2 \mathrm{~h}$ after ZD1839 or vehicle dosing. Growth delays were calculated from the difference in time taken to achieve $\mathrm{RTV}_{4}$ between control and treated tumours.

\section{Statistical analyses}

Mann-Whitney $U$ or 2-tailed paired Student's $t$-tests were used to evaluate the significance of the results obtained. Statistical analysis was performed using SPSS for Windows (Version 8).

\section{RESULTS}

\section{Antiproliferative effect of ZD1839 in combination with radiation in LoVo human colorectal cancer cells treated in vitro}

Recent studies have shown that inhibition of EGFR-linked MAPK activation can have profound effects on proliferation following radiation treatment in vitro (Dent et al, 1999; Reardon et al, 1999). To ascertain whether inhibition of the TK activity of EGFR using ZD1839 influences the proliferation of LoVo cells following radiation, cells were exposed to ZD1839 continually for 6 days, either alone, or in combination with three 2 Gy doses of radiation administered at $24 \mathrm{~h}$ intervals on days $1-3$ of the experiment. In keeping with previous studies (Dent et al, 1999; Reardon et al, 1999), relative proliferation in irradiated $v s$ sham-irradiated controls was evaluated by MTT assay. In the sham-irradiated controls, the doses of ZD1839 used had no significant effect on proliferation even at the highest concentration examined $(0.5 \mu \mathrm{M}$; $P=0.35$; Figure 1$)$. Treatment with radiation alone $(3 \times 2 \mathrm{~Gy})$ reduced cell proliferation although this did not reach statistical significance $(P=0.14)$. However, the combination of ZD1839 with irradiation led to a drug dose-dependent increase in growth inhibition compared with that seen following radiation alone (Figure 1), which was statistically significant at 0.2 and $0.5 \mu \mathrm{M}$ drug concentrations ( $P=0.03$ and 0.002 , respectively; 2 -tailed $t$-test).

\section{Radiation response of LoVo cells when grown as xenografts in nude mice}

Our in vitro observations supported an evaluation of the effect of ZD1839 on the radiation response of LoVo cells when grown as xenografts in nude mice. Initial studies were undertaken to ascertain the inherent radioresponsiveness of the LoVo xenograft model. Tumours of size $220-280 \mathrm{~mm}^{3}$ were irradiated at 5,10 and $15 \mathrm{~Gy}$ and the time to achieve $\mathrm{RTV}_{4}$ determined following each dose (Figure 2). The average (s.e.m.) growth delay achieved was $5.0( \pm 1.2)$ and $18.5( \pm 2.2)$ days for the 5 and 10 Gy groups, and more than 35 days for the group treated with $15 \mathrm{~Gy}$. For the latter group, the experiment was terminated 50 days after treat-

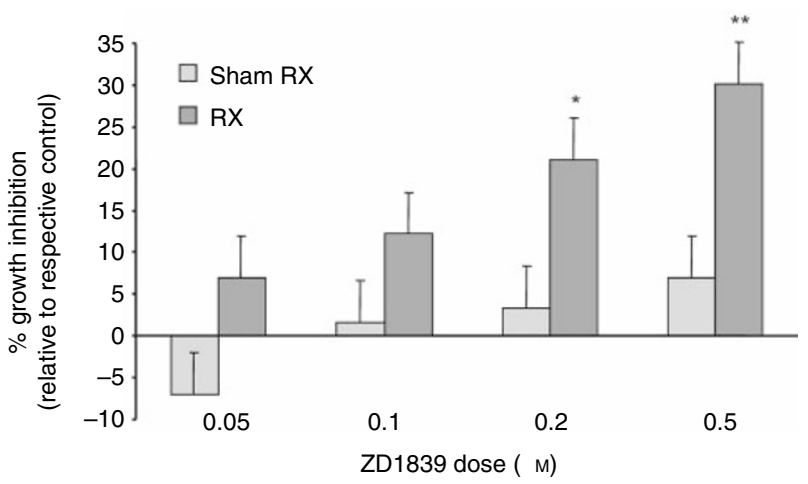

Figure I Enhanced growth-inhibitory effect of ZD I 839 when combined with radiation in vitro. ZD I839-induced growth inhibition was examined in the LoVo cell line with $(R x)$ or without (sham $R x$ ) additional radiation treatment. LoVo cells were exposed to ZD 1839 for a period of 6 days, with or without $3 \times 2$ Gy radiation administered on days I -3 of drug treatment. Cells were then treated with MTT for $4 \mathrm{~h}$, lysed with DMSO and the optical density $(O D)$ of the resulting solution determined using a multi-well plate reader. Growth inhibition normalised to the relevant control (i.e. ZDI839 treatment alone related to sham-treated control and ZDI839+radiation related to treatment with radiation alone) was calculated in each independent experiment. Data presented are means (s.e.m.) from 4-5 individual experiments. $* P=0.03$; $* * P=0.02$ (2-tailed and $t$-test) 




Figure 2 Radiation-induced growth delay in LoVo tumour xenografts. Localised radiotherapy was administered to tumours of size 220-280 $\mathrm{mm}^{3}$ with five allocated per treatment group. Experiments were terminated when $\mathrm{RTV}_{4}$ was achieved. The arrow on the 15 Gy data point indicates that the mean time to achieve $\mathrm{RTV}_{4}$ was actually greater than 44 days as the whole experiment was terminated 50 days after treatment, at which point $\mathrm{RTV}_{4}$ had been achieved in only three of the five mice treated with this dose. The data represent mean values (s.e.m.).

ment, when $\mathrm{RTV}_{4}$ had been achieved in three of the five treated tumours.

\section{ZD1839 enhances the response of LoVo xenografts to radiotherapy in vivo}

To ascertain whether ZD1839 had any effect on the response of LoVo tumours to single-dose radiotherapy, a 5 Gy radiation dose was selected for use in combination with $100 \mathrm{mg} \mathrm{kg}^{-1}$ ZD1839. Previous studies had demonstrated that this dose of drug administered daily for 14 days would give approximately the same growth delay as that achieved with $5 \mathrm{~Gy}$ in the LoVo xenograft model (data not shown). The response of the LoVo xenografts to $5 \mathrm{~Gy}$ plus ZD1839 was significantly enhanced compared with that seen with either drug or radiotherapy alone (Figure 3A,B, Table 1). From the LoVo radiation dose response curve, the time to achieve $\mathrm{RTV}_{4}$ for ZD1839 plus 5 Gy was equivalent to that which would be obtained for a single dose of $8 \mathrm{~Gy}$, giving a radiation dose modification factor of 1.6 for the combined therapy.

The effect of $100 \mathrm{mg} \mathrm{kg}^{-1} \mathrm{ZD} 1839$ for 14 days was then evaluated when combined with a fractionated radiation dosing protocol. Again, tumours treated with three $2 \mathrm{~Gy}$ fractions at $24 \mathrm{~h}$ intervals in combination with ZD1839 showed a significantly better response than those treated with radiation or drug alone (Figure 3C,D, Table 1). This was also the case when compared with tumours treated with 2 Gy fractions for a period of 5 days.

While the doses of radiation used were too low to elicit any normal tissue damage within the radiation field, some body weight losses were associated with ZD1839 treatment alone (Table 1). Encouragingly, no significant difference was apparent between the weight-loss observed in mice receiving only ZD1839 and those receiving the combined treatment (Table 1). In general, the nadir weight was seen 7-9 days into the 14 day treatment period. In approximately $85 \%$ of animals treated with ZD1839, with or without combined irradiation, there was a gradual recovery of weight through the remainder of the ZD1839 dosing period. The weight of the remaining animals stabilised and then increased once drug dosing had been stopped.

\section{DISCUSSION}

The EGFR has emerged as a key target for anticancer therapeutics. This view has evolved through studies correlating EGFR expression with disease progression in multiple tumour types (Sainsbury et al, 1987; Salomon et al, 1995; Maurizi et al, 1996; Dong et al, 1998)
A
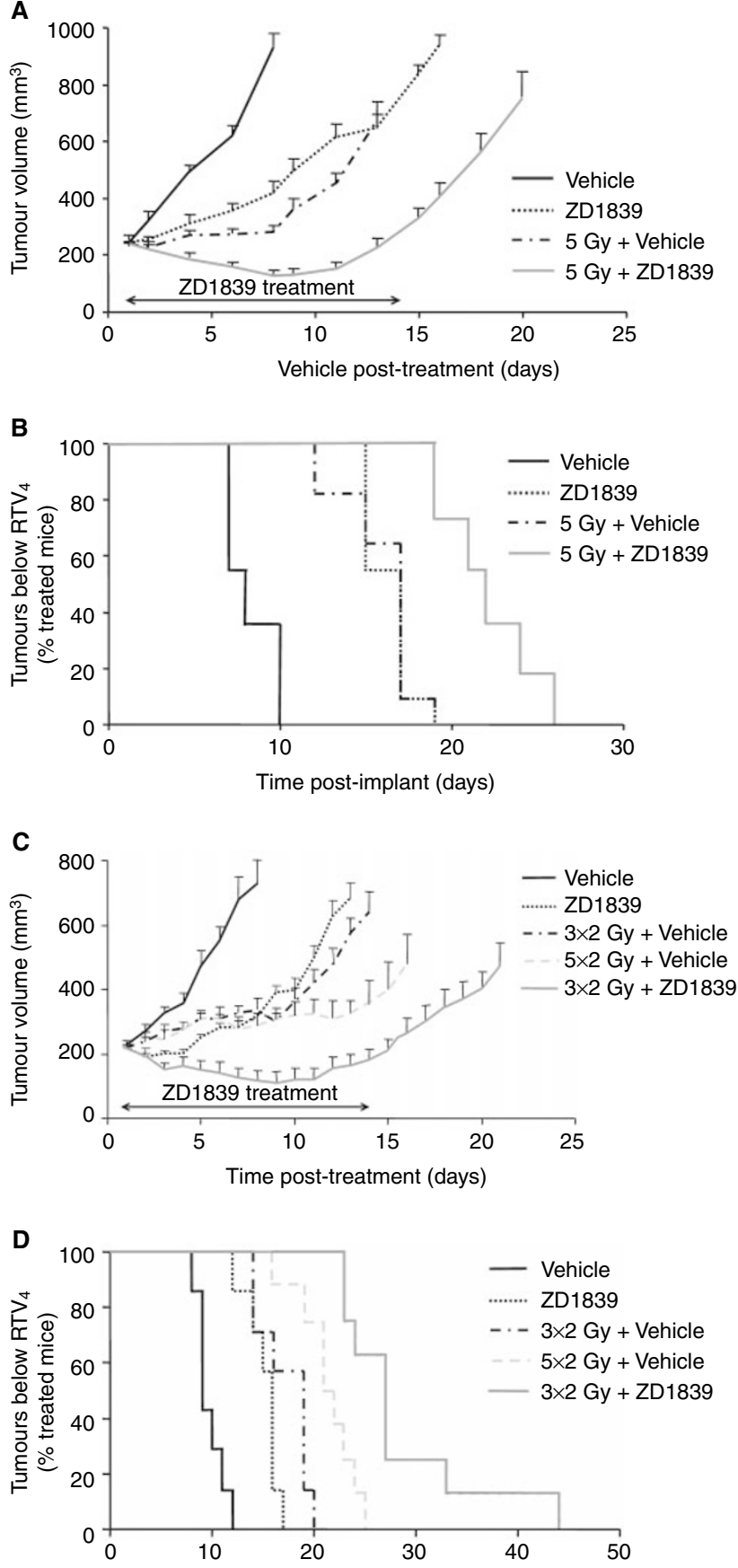

Figure 3 ZD 839 improves the anti-tumour effect of both single $(\mathbf{A}$ and B) and fractionated (C and $\mathbf{D})$ dose radiotherapy in LoVo tumour xenografts. ZDI 839 (I 00 mg kg day; po) or vehicle (0.5\% polysorbate) was administered for 14 days either alone or combined with a single dose of 5 Gy (A and $\mathbf{B}$ ) or three fractions of $2 \mathrm{~Gy}$ at $24 \mathrm{~h}$ intervals (C and $\mathbf{D})$. Radiation was administered $2 \mathrm{~h}$ after the first dose of ZDI 839 or vehicle and tumour size monitored until RTV 4 was achieved. A and $\mathbf{C}$ represent the mean size (s.e.m.) of the tumours within each treatment group $(n=7-$ I I, see Table I for details), up until the point when any tumour within the treatment group reached $\mathrm{RTV}_{4}$. The bar indicates the period of ZDI839 dosing. B and $\mathbf{D}$ give a diagrammatic representation of the time taken for each individual tumour within the treatment groups to achieve RTV ${ }_{4}$

and evidence that EGFR-inhibition can influence a diverse range of pathways, including those involved in proliferation, reduced apoptosis, angiogenesis and invasion (Woodburn, 1999). Approaches to inhibit EGFR activation include the development 
Table I Effect of ZDI839 combined with radiotherapy compared with either agent alone. Mice bearing LoVo xenografts of $220-280 \mathrm{~mm}^{3}$ were treated with ZDI839 (I00 mg kg day; po) or $0.5 \%$ polysorbate vehicle for 14 days either alone or combined with single- or fractionated-dose radiotherapy. Radiation was administered $2 \mathrm{~h}$ after drug or vehicle. Fractions were given at $24 \mathrm{~h}$ intervals

\begin{tabular}{|c|c|c|c|c|}
\hline Treatment & Number & $\begin{array}{l}\text { Nadir weight } \\
\left(\% \mathrm{~T}_{0}^{\mathrm{a}} \text { mean) }\right.\end{array}$ & $\begin{array}{l}\text { T/C } \\
\left(\%^{b}\right)\end{array}$ & $\begin{array}{l}\text { Mean (s.e.m. } \\
\text { time to } \\
\operatorname{RTV}_{4} \text { (days) }\end{array}$ \\
\hline \multicolumn{5}{|l|}{ Protocol I } \\
\hline Vehicle & 11 & 100 & 100 & $7.4(0.4)$ \\
\hline ZDI839 & 11 & 91 & 45 & $15.2(0.4)$ \\
\hline Vehicle+5 Gy & 11 & 95 & 30 & $15.0(0.6)$ \\
\hline ZDI839+5 Gy & 11 & $89^{c}$ & 14 & $21.5(0.4)^{d}$ \\
\hline \multicolumn{5}{|l|}{ Protocol 2} \\
\hline Vehicle & 7 & 99 & 100 & $9.8(0.6)$ \\
\hline ZDI839 & 7 & 89 & 42 & $14.9(0.7)$ \\
\hline Vehicle $+3 \times 2$ Gy & 7 & 96 & 48 & $17.2(1.1)$ \\
\hline Vehicle $+5 \times 2$ Gy & 8 & 92 & 41 & $21.4(1.1)$ \\
\hline ZDI $839+3 \times 2$ Gy & 8 & $87^{\mathrm{e}}$ & 18 & $28.5(2.7)^{f}$ \\
\hline
\end{tabular}

${ }^{\mathrm{a}} \mathrm{T}_{0}$, start of treatment. ${ }^{\mathrm{b}} \mathrm{T} / \mathrm{C}$ (treated/control) is the size of the treated tumours as a per cent of the vehicle-only tumours when the first tumour was excised in the latter group. ${ }^{c} P=0.502$ compared with ZD I 839 alone, 2 -tailed $t$-test. ${ }^{d} P<0.00$ I compared with vehicle +5 Gy or ZDI839 alone, 2-tailed $t$-test. ${ }^{e} P=0.353$ compared with ZDI839 alone, Mann-Whitney $U$-test. ${ }^{f} P=0.001$ compared with vehicle $+3 \times 2$ Gy or ZDI839 alone, and $P=0.007$ compared with vehicle $+5 \times 2$ Gy, Mann-Whitney U-test. NA, not applicable.

of anti-EGFR antibodies (Mendelsohn, 1997 (review), Yang et al, 1999) or small molecule inhibitors of the EGFR-tyrosine kinase (Ciardiello, 2000a), such as ZD1839.

EGFR is stimulated by a number of autocrine growth factors, including EGF and TGF $\alpha$. Recently, it has been shown that ionising radiation stimulates EGFR activation and cellular proliferation (Schmidt-Ullrich et al, 1997; Dent et al, 1999; Reardon et al, 1999; Todd et al, 1999) and that anti-EGFR antibody approaches can improve tumour radiation response (Saleh et al, 1999; Bianco et al, 2000; Milas et al, 2000). In the present study, we evaluated the potential influence of ZD1839 on the radiation response of the human colorectal carcinoma cell line LoVo which has moderate levels of EGFR expression (33000 receptors per cell), and is therefore likely to be representative of most epithelial tumour cell lines (Caraglia et al, 1994).

Initial in vitro studies demonstrated a clear antiproliferative effect of ZD1839 when combined with fractionated radiation treatment, using doses of ZD1839 that had no effect on cell growth when administered alone. These findings are in accordance with previously published studies, where radiation response was enhanced when combined with a dominant negative inhibitor of EGFR function (Contessa et al, 1999; Reardon et al, 1999).

A significant increase in antitumour activity was observed when ZD1839 was combined with radiotherapy in vivo. ZD1839 significantly enhanced the response of LoVo xenografts to both single-, and fractionated-dose radiotherapy $\left(P \leqslant 0.001, \mathrm{RTV}_{4}\right.$ values, Table $1)$. The effect of ZD1839 when combined with single-dose radiotherapy was equivalent to that obtained using a $60 \%$ increase in radiation dose. This dose modification would be translated into therapeutic gain if the normal tissue toxicities of radiation and ZD1839 do not overlap. It compares favourably with recent studies where radiation has been used in combination with cytotoxic agents, for example, gemcitabine, where a dose modification of 1.54 was achieved (Milas et al, 1999). The enhanced antitumour effect of fractionated radiotherapy when combined with ZD1839 was even more marked, with concommitant ZD1839 administra- tion being significantly better than a $67 \%$ increase in total radiation dose.

EGFR activation in response to radiation in vitro has been shown to be biphasic (Dent et al, 1999). The secondary response appears to be dependent on radiation-induced pro-TGF $\alpha$ cleavage and autocrine action of TGF $\alpha$. In vitro studies fail to demonstrate an antiproliferative effect of EGFR inhibition (using a dominant negative) following treatment with single doses of radiation (Contessa et al, 1999), but demonstrate clear effects in combination with fractionated radiation treatment, as seen in this and other studies (Contessa et al, 1999; Reardon et al, 1999). It is conceivable that the TGF $\alpha$-mediated autocrine effects may have a greater influence in vivo rather than in vitro.

The basis of the increased activity of ZD1839 when combined with fractionated radiotherapy in tumour xenografts may result from inhibition of EGFR-mediated accelerated re-population between fractions. Indeed, EGFR signalling has been previously linked with enhanced radiation-induced proliferation in cultured cells (Schmidt-Ullrich et al, 1997). In addition, ZD1839 alone has been previously demonstrated to have an antiproliferative effect when administered in vitro that has been associated with the induction of programmed cell death (Ciardiello et al, 2000b).

ZD1839 was administered daily by oral dosing for a 14 day period. Weight loss observed during the administration of ZD1839 was not influenced by radiotherapy. In most ZD1839-treated mice (with or without additional radiotherapy), following a nadir mid-way through the dosing period, weight was subsequently re-gained while ZD1839 was still being administered. Previous studies examining once-daily oral administration (days $1-5$ and $8-12$ ) of ZD1839 to nude mice bred on a NCR background, have documented body weight losses of around $5 \%$ with $100 \mathrm{mg} \mathrm{kg}^{-1}$ and up to $9 \%$ with $150 \mathrm{mg} \mathrm{kg}^{-1} \mathrm{ZD} 1839$ (Sirotnak et al, 2000). The slightly greater weight losses observed in the present study may reflect the greater duration of dosing and more chemo-sensitive nature of the nude mice used (cba background).

These data may have important clinical implications. ZD1839 is currently in Phase III development in non-small cell lung cancer, and has shown good tolerability and promising antitumour activity in Phase I studies in a variety of tumour types (Baselga et al, 2000; Ferry et al, 2000). The results of this study would support the use of ZD1839 in combination with radiotherapy in a clinical setting. Elevated EGFR expression has been demonstrated in lung, breast, head and neck, colorectal, oesophageal, prostate and pancreatic tumours (Salomon et al, 1995), in which radiotherapy (with or without surgery) is a primary treatment modality (DeVita et al, 1997; Yan et al, 2000). In addition, an inverse correlation between EGFR expression and the radiation cure rates of syngeneic murine tumours of different tissue origin has been demonstrated in preclinical studies (Akimoto et al, 1999). The doses of radiotherapy examined in this study were insufficient to elicit acute normal tissue toxicity in the radiation field. Provided there is no unacceptable potentiation of radiation toxicity in normal tissues, the combination of ZD1839 with radiotherapy could significantly enhance treatment response. The combination may also enable the radiotherapy dose to be reduced without diminishing curative potential, thus limiting radiation morbidity.

\section{ACKNOWLEDGEMENTS}

Thanks are due to Dr Mark Saunders for helpful discussions in the preparation of this manuscript. 'Iressa' is a trademark of the AstraZeneca group of companies. 


\section{REFERENCES}

Akimoto T, Hunter NR, Buchmiller L, Mason K, Ang KK, Milas L (1999) Inverse relationship between epidermal growth factor receptor expression and radiocurability of murine carcinomas. Clin Cancer Res 5: 2884-2890

Baselga J, Herbst R, LoRusso P, Rischin D, Ranson M, Plummer R, Raymond E, Maddox A-M, Kaye SB, Kieback DG, Harris A, Ochs J (2000) Continuous administration of ZD1839 (Iressa), a novel oral epidermal growth factor receptor tyrosine kinase inhibitor (EGFR-TKI), in patients with five selected tumour types: evidence of good tolerability. Proc Am Soc Clin Oncol 19: 177 a 686

Bianco C, Bianco R, Tortora G, Damiano V, Guerrieri P, Montemaggi P, Mendelsohn J, De Placeido S, Bianco AR, Ciardiello F (2000) Antitumor activity of combined treatment of human cancer cells with ionizing radiation and anti-epidermal growth factor receptor monoclonal antibody C225 plus type I protein kinase A antisense oligonucleotide. Clin Cancer Res 6: $4343-4350$

Caraglia M, Pinto A, Correale P, Zagonel V, Genua G, Leardi A, Pepe S, Bianco AR, Tagliaferri P (1994) 5-Aza-2'-deoxycytidine induces growth inhibition and upregulation of epidermal growth factor receptor on human epithelial cancer cells. Ann Oncol 5: 269-276

Carmichael J, DeGraff WG, Gazdar AF, Minna JD, Mitchell JB (1987) Evaluation of a tetrazolium-based semiautomated colorimetric assay: assessment of radiosensitivity. Cancer Res 47: $943-946$

Ciardiello F (2000a) Epidermal growth factor receptor tyrosine kinase inhibitors as anticancer agents. Drugs 60 (Suppl 1): 25-32; discussion 41-42

Ciardiello F, Caputo R, Bianco R, Damiano V, Pomatico G, De Placido S, Bianco AR, Tortora G (2000b) Antitumour effect and potentiation of cytotoxic drugs activity in human cancer cells by ZD-1839 (Iressa), an epidermal growth factor receptor-selective tyrosine kinase inhibitor. Clin Cancer Res 6: $2053-2063$

Contessa JN, Reardon DB, Todd D, Dent P, Mikkelsen RB, Valerie K, Bowers GD, Schmidt-Ullrich RK (1999) The inducible expression of dominantnegative epidermal growth factor receptor-CD533 results in radiosensitization of human mammary carcinoma cells. Clin Cancer Res 5: 405-411

Dent P, Reardon DB, Park JS, Bowers G, Logsdon C, Valerie K, SchmidtUllrich RK (1999) Radiation-induced release of transforming growth factor activates the epidermal growth factor receptor and mitogen-activated protein kinase pathway in carcinoma cells, leading to increased proliferation and protection from radiation-induced cell death. Mol Biol Cell 10: 2493-2506

DeVita VT, Hellman S, Rosenberg SA (eds) (1997) Cancer: Principles and practice of oncology. 5th edn, New York: Lippincott-Raven

Dong M, Nio Y, Guo KJ, Tamura K, Tian YL, Dong YT (1998) Epidermal growth factor and its receptor as prognostic indicators in Chinese patients with pancreatic cancer. Anticancer Res 18: 4613-4619

Ferry D, Hammond L, Ranson M, Kris MG, Miller V, Murray P, Tullo A, Feyereislova A, Averbuch S, Rowinsky E (2000) Intermittent oral ZD1839 (Iressa), a novel epidermal growth factor receptor tyrosine kinase inhibitor (EGFR-TKI), shows evidence of good tolerability and activity: final results from a Phase I study. Proc Am Soc Clin Oncol 19: 5E (3a)

Maurizi M, Almadori G, Ferrandina G, Distefano M, Romanini ME, Cadoni G, Benedetti-Pancini P, Paludetti G, Scambia G, Mancuso S (1996) Prognostic significance of epidermal growth factor receptor in laryngeal squamous cell carcinoma. Br J Cancer 74: 1253-1257
Mendelsohn J (1997) Epidermal growth factor receptor inhibition by a monoclonal antibody as anticancer therapy. Clin Cancer Res 3: 2703-2707

Milas L, Fujii T, Hunter N, Elshaikh M, Mason K, Plunkett W, Ang KK, Hittelman W (1999) Enhancement of tumor radioresponse in vivo by gemcitabine. Cancer Res 59: 107-114

Milas L, Mason K, Hunter N, Peterson S, Yamakawa M, Ang K, Mendelsohn J, Fan Z (2000) In vivo enhancement of tumour radioresponse by C225 antiepidermal growth factor receptor antibody. Clin Cancer Res 6: $701-$ 708

Reardon DB, Contessa JN, Mikkelsen RB, Valerie K, Amir C, Dent P, Schmidt-Ullrich RK (1999) Dominant negative EGFR-CD533 and inhibition of MAPK modify JNK1 activation and enhance radiation toxicity of human mammary carcinoma cells. Oncogene 18: 4756-4766

Sainsbury JR, Farndon JR, Needham GK, Malcolm AJ, Harris AL (1987) Epidermal-growth-factor receptor status as predictor of early recurrence of and death from breast cancer. Lancet 1: 1398-1402

Saleh MN, Raisch KP, Stackhouse MA, Grizzle WE, Bonner JA, Mayo MS, Kim HG, Meredith RF, Wheeler RH, Buchsbaum DJ (1999) Combined modality therapy of A431 human epidermoid cancer using anti-EGFr antibody C225 and radiation. Cancer Biother Radiopharm 14: $451-463$

Salomon DS, Brandt R, Ciardiello F, Normanno N (1995) Epidermal growth factor related peptides and their receptors in human malignancies. Crit Rev Oncol Hematol 19: 183-232

Schmidt-Ullrich RK, Mikkelsen RB, Dent P, Todd DG, Valerie K, Kavanagh BD, Contessa JN, Rorrer WK, Chen PB (1997) Radiation-induced proliferation of human A431 squamous carcinoma cells is dependent on EGFR tyrosine phosphorylation. Oncogene 15: 1191-1197

Sheldon PW, Hill SA (1977) Hypoxic cell radiosensitisation and local control by x-ray of a transplanted tumour in mice. Br J Cancer 35: 795-808

Sirotnak FM, Zakowski MF, Miller VA, Scher HI, Kris MG (2000) Efficacy of cytotoxic agents against human tumour xenografts is markedly enhanced by coadministration of ZD1839 (Iressa) an inhibitor of EGFR tyrosine kinase. Clin Cancer Res 6: 4885-4892

Todd DG, Mikkleson RB, Rorrer WK, Valerie K, Schmidt-Ullrich RK (1999) Ionizing radiation stimulates existing signal transduction pathways involving the activation of epidermal growth factor receptor and ERBB-3, and changes of intracellular calcium in A431 human squamous carcinoma cells. J Recept Signal Transduct Res 19: 885-908

Woodburn JR (1999) The epidermal growth factor receptor and its inhibition in cancer therapy. Pharmacol Ther 82: $241-250$

Workman P, Twentyman P, Balkwill F, Balmain A, Chaplin D, Double J, Embleton J, Newell D, Raymond R, Stables J, Stephens T, Wallace J (1998) United Kingdom Co-ordinating Committee on Cancer Research (UKCCCR) Guidelines for the Welfare of Animals in Experimental Neoplasia 2nd edn. Br J Cancer 77: 1-10

Yan Y, Carvalhal GF, Catalona WJ, Young JD (2000) Primary treatment choices for men with clinically localized prostate carcinoma detected by screening. Cancer 88: $1122-1130$

Yang XD, Jia XC, Corvalan JR, Wang P, Davis CG, Jakobovits A (1999) Eradication of established tumours by a fully human monoclonal antibody to the epidermal growth factor receptor without concomitant chemotherapy. Cancer Res 59: $1236-1243$ 